У, $\triangle \mathrm{K} 65$

ББК 60.822

DOI 10.22394/1682-2358-2019-1-68-77

S.M. Fedyunina, Doctor of Sciences (Sociology), Head of the Social Communications Department, Povolzhsky Institute of Management named after P.A. Stolypin, Branch of the Russian Presidential Academy of National Economy and Public Administration

A.V. Fedorova, Candidate of Sciences (Pbilosophy), Docent of the Social Communications Department, Povolzhsky Institute of Management named after P.A. Stolypin, Branch of the Russian Presidential Academy of National Economy and Public Administration

\section{MANAGEMENT OF RISKS \\ AND COMMUNICATION PRACTICES OF MODERNITY}

The process of managing risks and communication practices in the context of modernity is analyzed. Communicative practices that play the role of external and internal content of the risk management process in the current situation are considered. For the studies of the connectedness of risks and communicative practices of our time, the methodology and discursive practices of John Law are used.

Key words and word-combinations: communications, risks, management, modernity, John Law.
С.М. Федюнина, доктор сощиологиеских наук, заведуюший кафедрой сочиальньхх коммуникачий Поволжского института управления имени П.А. Стольтина - фихиала Российской академии народного хозяйства и государственной службь при Президенте РФ (email: smf777@bk.ru)

A.B. Федорова, кандидат философских наук, дочент кафедрь сочиальньх ком-муникаиий Поволжского института упрабления имени П.А. Стовтина - филиала Российской академии народного хозяйстьа и государственной службь при Президенте РФ (email: anna_fedorova_76@list.ru)

\section{УПРАВАЕНИЕ РИСКАМИ И КОММУНИКАТИВНЫМИ ПРАКТИКАМИ СОВРЕМЕННОСТИ}

\begin{abstract}
Аннотация. Анализируется процесс управления рисками и коммуникативными практиками в контексте современности. Рассматриваются коммуникативные практики, выступающие в роли внешнего и внутреннего контента процесса управления рисками в современной ситуации. Для исследований связанности рисков и коммуникативных практик современности использована методология и дискурсивные практики Джона Ло.

Ключевые слова и словосочетания: коммуникации, риски, управление, со-временность, Джон Ло.

B равления рисками и коммуникативными практиками выступает современность, ее уникальные и инвариантные характеристики. Коммуникативные практики - это стремления и установки акторов совре-
\end{abstract}


менной реальности, которые выстраивают диалог с современностью и непрерывно совершенствуют его с помощью собственных действий в условиях грамотного управцения рисками. Коммуникативные практики интерпретируются в традиции Ю. Хабермаса, где используются модели коммуникативного действия [1, с. 324-340]. Коммуникативные практики - это действия, главными интенциальными установками которых явцяются ориентация на взаимопонимание и согласие. Они включают в себя процесс соотнесения с фоновыми практиками жкизненного мира и с различными сферами референций (знаниями, нормами, оценками и чувствами). Соответственно, Амя осуществления эффективного управления коммуникативными практиками необходимо формировать и развивать условия и ресурсы дия взаимопонимания акторов, смысловые референџии (претензии на значимость), структуры Аиалога, разноплановые понимания современности, нормативные структуры Аействий, культуру позиџионирования и эмоџионацьный интемлект, интуиции и чувственную сферу современных акторов. С проџессами формирования и развития структур коммуникативных действий связаны риски, понимаемые как совокупность возможностей, открывающихся акторам коммуникативных практик в границах современности. Необходимо учитывать вероятностный (контингентный) характер отношений межАу управлением рисками и коммуникативными практиками. С одной стороны, управление рисками служит фоновыми практиками по отношению к коммуникациям. С Аругой стороны, управление рисками встроено в коммуникативные практики.

В процессе управления рисками необходимо выстраивать структуры коммуникативных действий, проводить системную рефлексию, на основе которой планируется осуществлять управление. Управление рисками - это сложный, открытый, некинейный и современный процесс реализаџии рискстратегий - снижения, повышения, принятия и распределения рисков. Рассмотрим современные риски системно, то есть ситуацию, процесс, событие и действия акторов, направленные на преодоление неопределенности, сложности и разнообразия, возникающие в современном мире, последствиями которых могут стать угрозы, опасности и ущерб или новые тренды, возможности, перспективы. Риск, анализируемый в качестве ситуации риска, вкАючает в себя источники рисков, они носят общий и фундаментальный характер. Условия рисков вытекают из источников риска и детерминированы ими, они более конкретны. Факторы рисков, определяющиеся

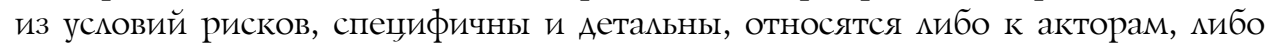
к их деятельности. Субъекты риска - это акторы, занимающие активные позиции по отношению к стратегиям управления рисками, принимающие на себя ответственность за риски. Объекты рисков представцяют собой акторов, выполняющих пассивную роль по отношению к рискам. Виды рисков, включающие систему действий акторов, позиции и роли, а также прогнозируемые последствия, опреАеляют стратегии рисков, выстраиваемые по формуле «что необходимо предпринять... и Амя чего...» [2] .

Аля современной ситуаџии неАостаточно, на наш взгляА, опреАемять риски как произведение вероятности того или иного события на возможкный ущерб 
от него. Текстуры страхов, надежА, радости не схватываются академическими методами исследований. В каждом эмементе риска присутствует эсхатологическая составляющая, надежда на «спасение в последний момент». В рисках в явной или неявной форме выражена установка акторов на то, что несмотря на возможные неблагоприятные исходы, может быть, удастся преодолеть их при благоприятных исходах и событиях [3]. В этой надежде присутствуют не только установки и настроения, но и коммуникативные действия - жемание Аоговориться с самой сложной из всех видов реальностей - повсеАневной реальностью. Эффективность коммуникативных практик определяется подобием сложности, нелинейности, слабой прогнозируемостью событий и феноменов современности акторами, осуществмяющими коммуникативные взаимодействия.

Контингенции, существующие между коммуникативными практиками и рисками, проявцяют себя в амбивалентности рисков. Интерпретации современных рисков в качестве угроз и потерь привычны и ингерентны культуре современного общества. У нас «грустная культура», мы склонны придерживаться пессимистичных стратегий и исходов Аействий акторов. К важным угрозам относят риски прерывности коммуникативных действий, связанные с фрагментаџией опыта и знаний, методологий и технологий, репрезентащий и Аискурсов, коммуникативных практик.

Феномен прерывности связан с разрывом в деятельности акторов, в смысмовых характеристиках, в процессе передачи значений. Он может быть исследован с помощью анализа противоположного ему феномена непрерывности. Непрерывной явмяется повседневная реальность с присущими ей структурными феноменами и отношениями. Современность - это непрерывность событийного ряда (частный случай - коммуникативные практики), участниками и очевидџами которой мы являемся. Кажущаяся непрерывность позволяет наблюдать и участвовать в пролонгированных событиях. У акторов возникает имюзия Алительности, определенности и статичности (стабильности и безопасности коммуникативных практик). М. Фуко писал о непрерывности историков: «Вот уже несколько десятияетий внимание историков направлено на периоды большой Алительности, словно за политическими перипетиями и их отдельными эпизодами они рассчитывают обнаружкить устойчивые и труАнонарушимые равновесия, необратимые проџессы, постоянно наблюдаемые факты регуляции; явления, имеющие общую тенденцию, Аостигающие наивысшей точки и оборачивающиеся вспять после многовекового непрерывного существования; Авижения накопиения и медленного насыщения; огромные неподвижные и немые цоколи, скрытые поА толщей событий путаниџей траАиционных повествований» [4, с. 35].

Непрерывность позволяет найти закономерности разворачивающейся и стремительно развивающейся реальности, реальности управления рисками и коммуникативными практиками. Закономерности усиливают скрепы межАу рутинизированными практиками и системами отношений, формируют определенность акторов и контекстов их жизни (значимые условия и факторы, оказывающие доминирующее вцияние). В реацьности проявцяют себя 
не только Аискурсы прерывности, но Аискурсы разрыва, границы, фронтира. Аискурсы разрыва и разцичения проработаны Н. Ауманом, дискурсы граниџ ингерентны теории фреймов и фрейм-анализу И. Гофмана. Понятие фронтира по отношению к рискам и коммуникативным практикам можно использовать в качестве метафоры, раскрывающей новые исследовательские горизонты. Традиционно под «фронтиром» понимают границу между освоенными и неосвоенными поселенцами землями. Эффективность управления рисками и коммуникативными практиками во многом обусловлена динамично изменяющимися границами и фронтирами между явленными феноменами и скрытыми текстурами.

Современность неупорядочена, сложна, нелинейна, противоречива и отмичается особым типом связанности проџессов и явлений в условиях темпоральной и информационной неопределенности. Она бросает вызовы акторам, которые принимают участие в управлении рисками и коммуникативными практиками. Задача современных акторов (человека, отдельных организаций) - Аостойно ответить на эти вызовы [5; 6]. Современное общество столкнулось с совершенно новыми пост-глобальными, пост-сетевыми и пост-информационными вызовами. К важным последствиям этих вызовов можно отнести онтологическую, аксиологическую, гносеологическую и праксеологическую фрагментарность современных коммуникативных практик, антропологическую катастрофу, гносеологический кризис (кризис познания, методологический кризис), отсутствие Аолжного уровня и культуры рефлексии. Актуальность «вызовов» в современной ситуации связана с феноменами Алинной турбулентности, неминейности, открытости, рекурсивности, высокой неопределенности среды, а также высоким уровнем рисков.

Формированию, поддержанию и развитию этих характеристик способствует кризис, формирующий новую системность в процессах управления рисками и коммуникативными практиками. Новая системность современного кризиса проявляется в его пролонгированном характере, охвате всех сфер общественной жкизни и социальных отношений с явным Аоминированием помитической сферы. Кризис непредсказуем по своим послеАствиям, приводит к резким изменениям основных показателей политической, экономической, социальной, технологической и организационно-управленческой жизни. Современный кризис коррелирует с высокими рисками и тяжелыми последствиями социальных действий, с ущербом и потерями. Коммуникативные практики реализуются в условиях кризисных проявлений и становятся менее формамизованными, поскольку формальные структуры и сощиальные институты не работают. Особое значение приобретают неформацьные коммуникации, отношения и конвенџии. Они становятся политически окрашенными в границах общества и в рамках как отдельных организаций, так и процессов общего и специального управления. Коммуникации протекают в ситуации компрессии времени и стремительно возрастающих темпов социальной жкизни акторов. Эффективные коммуникативные практики - это быстрые, короткие и смысмовые коммуникации, направленные на достижение результата с четкими инАикаторами. 
В сложившихся условиях становятся возможными маловероятные события, которые «не могут произойти никогда» («невозможные события» соџиальной и организационно-управленческой реальности). Эти процессы происходят бцагодаря способности современных соџиальных, организаџионно-управленческих и коммуникативных рисков многократно усиливаться, сопровождая в качестве эпифеноменов социальное и организаџионное функционирование и развитие. С Аругой стороны, риски на основе контингентных связей и отношений коррелируют не только межАу собой, аккумулируя эффекты от различных видов рисков, но и с коммуникативными практиками. Аюбые коммуникаџии значительно повышают риски.

Современность не просто противоречива, она проблемно ориентирована. Противоречия современной ситуации не имеют ни малейшего совпадения с полярностью или амбивалентностью. Противоречивость в большей степени связана со смешениями рисков и коммуникативных практик, с многочисленными беспорядками. Онтологическими основаниями функщионирования и развития современности явмяются неопределенность, кризисность, высокая рискогенность, и присутствие коммуникативных практик как трудно уловимых текстур. Эти характеристики присущи современности априори, в сику того, что она является современностью. Они могут быть представлены в явном ияи матентном виде.

Современность скрывает неявные текстуры процессов управления рисками и коммуникативными практиками. Тогда мы начинаем задаваться вопросом: насколько важны для нас ускользающие, потоковые текстуры практик? Познаваемы ми в принџипе риски и коммуникации современности? Какую цену мы платим за познание рисков и коммуникативных практик в аспекте современности? Чтобы ответить на поставленные вопросы, во-первых, необходимо преодолеть академическое предпочтение результатов проџессу исследований. Аля этого следует отказаться от конџепта безопасности в управлении рисками и коммуникативными практиками, осуществить выбор в пользу неопределенностей и неразрешимостей.

Во-вторых, важно искмючить симметрию в качестве исследовательского принципа в духе европейско-американской традиџии. Традиционные подходы, с опорой на количественные методы исследований, устанавливают четкие правияа, алгоритмы и проџедуры. На основании установленных правиц определяются правильное ици неправильное использование тех или иных методов, получаемых результатов и отчетов. Методы и результаты жестко детерминированы: хорошие и правильные методы могут дать верные результаты. Современный исследователь, Аж. Ао пишет: «Если мы хотим понять наши методы, то нам мучше рассматривать их систематически, исследовать их без предварительной оџенки их адекватности в терминах наших допущений о том, что методологически правильно, а что - нет» [7, с. 313].

B-третьих, необходимо признать множественность практик, порождающих, в свою очередь, множественные реалии. Истина перестает выполнять роль еАинственного арбитра в управлении рисками и коммуникативными практиками. Истина перестает быть единственным бцагом, и мы можем выбирать между жекаемым развитием событий.

72 Bulletin of the Volga Region Institute of Administration • 2019. Vol. 19. № 1 
B-четвертых, в управлении рисками и коммуникативными практиками современности необходимо обладать подвижной рефлексивностью, способностью устанавливать и переустанавцивать подвижные граниџы между явными и неявными, скрытыми и иными текстурами действий и отношений.

В-пятых, важно переосмыслить понятие блага. Каким образом мы можем мыслить релевантно о различных благах - справедливости, Ауховности, политике, эстетике, вдохновении? Как отрефлексированные бцага могут взаимодействовать межАу собой в рамках управления рисками и коммуникативными практиками?

B-шестых, обратим внимание на «воображаемые объекты» (Аж. Ао) или «кентавр-объекты», «искусственные объекты» (Г.П. ЩеАровицкий). Объекты (управление рисками и коммуникативными практиками) изменяются от топоса к топосу. Есть различные пространства, связанные с этими объектами, множественные реалии и соответствуюшие им множественные объекты. Они каждый раз конструируются заново. Управление рисками и коммуникативными практиками нарративно. Нарративы прописываются на основе праксеографии. Седьмой принцип связан с материальностью. Насколько управление рисками и коммуникативными практиками домжно быть материально, здесьприсутствующим? Аолжны ми мы выходить в Аругие модальности более щеАрых и длинных по времени, трудоемких и нарративных, качественных методов? Можем ми мы в управлении рисками и коммуникативными практиками задействовать не только тексты и цифры, но и тела, приборы, здания?

Восьмой принцип управления рисками и коммуникативными практиками современности заключается в том, чтобы открыть окна неопределенности, проявить ее в дискурсах, не ориентироваться на определенные результаты и целевые установки. Стремление к ясности, опредеменности, безопасности, к низким рискам становится слишком большим слерживающим ограничением.

На основе девятого принщипа «пере-учреждения» можно отказаться от дуализма, переопределить роль активности акторов в управлении рисками и коммуникативными практиками. Активность акторов риска и коммуникативных практик больше не явмяется независимой от современных реалий.

Слишком уж неуловима и изменчива, неустойчива и подвержена размичным смешениям современность, в граниџах которой протекает проџесс управления рисками и коммуникативными практиками. Современность не тождественна модусу настоящего. На наш взгмяА, недостаточно апемировать к М. Хайдеггеру и описывать современность через со-бытийность настоящего и со-участие акторов, со-вовлеченность, со-работничество через со-присутствие акторов. По своим текстурам современность бцизка к потоковым феноменам, трудным дмя процессов рефмексии, интерпретаций и описаний. Возникает важная проблематика, связанная с несформированностью дискурсов коммуникативных практик дмя описания современности. Например, сложно описать современность, используя метафору потоковости. В границах этого метафоричного поля современность отличается антропоџентричностью и телеологичностью. В центре современной ситуации «стоит» человек, актор, осуществляющий управление рисками и коммуникативными практиками. 
Антропоцентричность в процессе управления рисками и коммуникативными практиками преАполагает, что актор «встает» в цеентр современности или ее отдельного фрагмента и выстраивает ее изнутри, интегрируя в динамично разворачивающуюся реальность свои цели, мотивы, интересы и ценности, позиџии и стратегии, риски и коммуникации и другие помя, которые он может порождать бесконечно. Внешнее и внутреннее непрерывно переходят одно в Аругое и превращаются в трудные разцичения внутреннего и внешнего. Современный человек (актор) развивает внешнюю реальность через внутреннее и изменяет внутреннее через внешнее. Происходит смешение текстур действий и отношений.

Телеологичность современных акторов предполагает, что актор непрерывно выстраивает цеми по управлению рисками и коммуникативными практиками, делает это «без суеты». Важными явмяются два основных момента. Во-первых, постановка џемей - это џелостный и сложный процесс, основанием которого явмяется выбор актора, реализуюшего управление рисками и коммуникативными практиками. Он осознает, формирует и осуществмяет выбор того или иного процесса целеполагания. Текстуры выбора сложны по своим этическим и когнитивным основаниям. ГАавным основанием выбора современного актора выступает темпоральность (временнЫе особенности). Это серьезный «вызов», который актор Аолжен преодолеть. Выбор Аолжен быть произведен «без суеты», что фактически непреодолимо в условиях временной компрессии (насыщенность событиями единиџы объективного времени), возрастающих темпов социальной жизни и социальных действий, аритмии и ахронии. Вовторых, в телеологичности причинно-следственные связи могут быть направмены в обратную сторону (инверсия причин и последствий). Например, если я хочу стать исследователем рисков и коммуникативных практик, то мне необходимо научиться соответствующим подходам, модемям и инструментариям. Но имеют место и обратные причинно-следственные связи: мне нравится исследовать риски и коммуникации с помощью выбранного инструментария из-за того, что я приняла решение исследовать риски и коммуникации.

Важной особенностью современного проџесса управления рисками и коммуникативными практиками является способность разворачиваться и изменяться на непрерывных системно-организованных обратных связях. Обратная связь представмяет собой сложные навигационные системы с тонкими и точными приборами. Она, с одной стороны, отстраивает от реальности, а с Аругой - настраивает на следующий этап процесса управления рисками и коммуникативными практиками. Контуры обратной связи тесно связаны с феноменом памяти и воспроизведения тех или иных событий соџиальной жизни человека (актора). Память выступает в роли основы нового контура обратной связи. Мы можем воспроизвести событие только один раз, что доказано экспериментально когнитивными психологами [8]. Следующий акт воспоминания - это не воспоминание произошедшего события, а «воспоминание воспоминания», то есть следующий контур обратной связи выстраивается не на основании рефмексивного выхода за граниџы события, а на основе информации, предоставменной первым рефмексивным выходом.

74 Bulletin of the Volga Region Institute of Administration • 2019. Vol. 19. № 1 
Современность встроена в более широкий контекст исторического развития общества и общественных отношений. Ей присуща включенность в исторические периоды изменения соџиального знания и практик, связанных с ним. Чтобы не мишиться исторического контекста, необходимо вкцадываться в него концептуально, методологически и методически. К тому же необходимо концентрироваться на настоящем, погружаться в него полностью, переживая деятельность на глубинном уровне. Вместе с тем акторам современности важно не только контролировать сиюминутные действия, но и осуществлять выход в более широкие фреймы смыслов: «Необходимо иметь глобальную систему взаимосвязанных жизненных џемей, способную придать смысл каждому конкретному делу, которым занимается человек. Если просто переключаться с одного вида деятельности на Аругой безо всякой связи межАу ними и без глобальных перспектив, то, скорее всего, огмянувшись назаА на прожитую жизнь, вы не обнаружите в ней смысла» [9, с. 320-321].

Современность не просто проблемно ориентирована, она сложная и связанная, нелинейная и открытая, системная и непропорџиональная по оказываемым воздействиям на обстоятельства, факторы или условия. Наделяя столь уверенно современность инвариантными и уникальными свойствами или характеристиками, необходимо задаться вопросом: каким образом мы узнаем о них? «В последние два десятияетия приобрели значимость методы анализа визуального материала, перформативные подходы и понимание методов как поэтики или интервенџионистского нарратива» [7, с. 15]. Почему процесс познания в современном контексте становится нарративом, рассказом со встроенными структурами субъективного опыта того или иного актора? Каким образом должен быть выстроен этот рассказ, чтобы «вкцючиты» риски и коммуникативные практики в сложную и противоречивую реальность? Задача современного исследователя более сложная. Она заключается в том, чтобы не вычленить или выделить из ткани современной реальности анализа проџесс управления рисками и коммуникативными практиками, а напротив - «включить», «встроить», не разрушив важной и необходимой связности с Аругими феноменами и процессами современности. Возможно ки изменить сушествующую связность Аля того, чтобы проанализировать риски и коммуникативные практики в качестве сложных феноменов социальной реальности? Почему нарративы выступают в роли интервенций по отношению к современности и процессу управления?

Управление рисками и коммуникативными практиками не освоено топомогически, темпорально, процедурно и организационно. Основными причинами, на наш взгляА явцяются многообразные коннотаџии рисков и коммуникативных практик. Не определяются управленческие и другие виды рисков. Выявляются поля рисков (технические, человеческие, политические, экономические), а не конкретные виды рисков, по отношению к которым можно выстраивать и реализовывать управленческие стратегии. Отсутствуют четкие и ясные проекџионные матриџы восприятия рисков и коммуникативных практик, рабочих модекей, рекурсивных современным практикам. Риски рассматриваются в соответствии с ментальностью и исследовательской культурой 
искцючительно в качестве возможкных, угроз, потерь, вероятного ущерба от Аействий. Но есть и Аругой модус - риски как возможность совершенствования собственных практик. Сушествование рисков и коммуникативных практик как эпифеноменов социальной деятельности в повседневной реальности усложняет современность и проџессы управления. Необходимо ресурсно обеспечивать процесс управления рисками и коммуникативными практиками на различных управленческих уровнях от государственного до местного. Понимание рисков и коммуникативных практик в качестве сложных феноменов социальной и организационной жкизни, требует столь же сложных практик управления на основе понимания амбивалентности рисков и коммуникаџий [10; 11]. В современности не сформировано четкое понимание Аинамичных и сложных отношений и взаимосвязей, сушествующих межАу рисками и коммуникативными практиками. Важной причиной неэффективного управления рисками и коммуникативными практиками явцяется нерекурсивность культуры риска культуре управления коммуникативными практиками и авторитарной культуре управцения в России [12, с. 164].

Отметим, что стремление к безопасности и гарантии безопасности не снижают риски, напротив, в значительной степени повышают их, переключая внимание на концепт безопасности и увеличивая финансовые вложения в нее. В это время мы сталкиваемся с «упущенными рисками», поскольку вкцадываемся управленчески, психически и экономически в безопасность и опредеменность. На наш взгляА, безопасность - мишь незначительный, временный фрагмент практического опыта. Нужны новые фреймы, медленные и изменчивые, дия управления рисками и безопасностью: «Рискованный и тревожный процесс - понадобятся усилия, чтобы создать реалии и удержать их хоть на момент, в борьбе против потоков и неопределенности вокруг» [7, с. 30]. На стратегии грамотного управления рисками и коммуникативными практиками работает новый метоА, требующий картографического описания, - метоА картографии. Картография состоит из пяти основных этапов. На первом этапе происходит «наложение мест». Собираются разнообразные нарративы - описания происходящих событий в разАичных топосах и темпоральностях. Нарративы сравниваются и анализируются на основе веры в единый объект исследований. Мы верим, например, что риски и коммуникативные практики обкадают некоторыми инвариантными характеристиками. На втором этапе сведенные вместе нарративы служат для формирования единого, целостного и однородного нарратива. На третьем этапе - проблематизации и структурирования проблемного поля - осушествляются переводы межАу разцичными практиками и симптомами рисков и коммуникаций, выявцяются основные противоречия управления рисками и коммуникативными практиками. Это этап организаџии гетерогенных Аискурсов Аля писания рисков и коммуникативных практик. Четвертый этап - это этап иерархии тестов, когда одни диагностические проџеАуры превацируют наА Аругими, и им отдается преАпочтение по степени приоритетности. На пятом, завершающем, этапе выстраиваются рациональные объяснения явных размичений проџесса управления рисками и коммуникативными практиками.

76 Bulletin of the Volga Region Institute of Administration • 2019. Vol. 19. № 1 
Таким образом, управление рисками и коммуникативными практиками современности является сложным и нелинейным проџессом, рекурсивным особенностям настоящего времени. Этот процесс затрагивает неопределенность, современный кризис общества, а также вкмючает грамотные и системные стратегии управмения ими.

\section{Библиографический список}

1. Хабермас Ю. Моральное сознание и коммуникативное действие / пер. с нем. СПб., 2000.

2. Федорова А.В. Риск-мененджмент. М., 2018.

3. Хоружий С.С. Современность и эсхатология: Рене Жирар и парадигма спасения в последний миг // Вопросы философии. 2018. № 6. С. 111-120.

4. Фуко М. Археология знания. СПб., 2004.

5. Сравнительные политические исследования России и зарубежных стран. М., 2008.

6. Калдор М. Новые и старые войны: организованное насилие в глобальную эпоху / пер. с англ. А. Аполонова. М., 2015.

7. Ло Дж. После метода: беспорядок и социальная наука. М., 2015.

8. Черниговская T.B. Чеширская улыбка кота Шредингенра: язык и сознание. М., 2017.

9. Чиксентмихайи М. Поток: Психология оптимального переживания. М., 2015.

10. Федорова А.В., Хорольцева Е.Б. Риски рефлексивных коммуникаций в ситуации кризиса // Вестник Поволжского института управления. 2016. № 3(54). С. 102-110.

11. Федюнина С.M. Толерантность в поликультурном обществе ХІ века: миф или возможность сохранения цивилизации? // Вестник Поволжского института управления. 2015. № 2(47). C. 102-109.

12. Национальные проекты и реформы 2000-х годов: модернизация социальной политики / под ред. Е.Я. Ярской-Смирновой, М.А. Ворона. М., 2009. 